\title{
Exchange rate forecasts with the Michigan Quarterly Econometric Model of the US economy
}

\author{
E. Philip Howrey* \\ The University of Michigan, Ann Arbor, MI 48109, USA \\ Received February 1992, final version received January 1993
}

\begin{abstract}
Gandolfo et al. [Journal of Banking and Finance 14 (1990) 965-992] have shown that their continuous time model of the Italian economy produces better ex post out-of-sample forecasts of the lira/\$ exchange rate than either existing structural or random-walk models. When the Michigan Quarterly Econometric Model is used, it is found that ex post out-of-sample forecasts of the trade-weighted value of the US dollar produced by the model are also superior to forecasts of a random-walk model. However, ex ante forecasts in which all the exogenous as well as the endogenous variables are forecast are less accurate than those produced by the random walk. The price of imported goods in foreign currency, an exogenous variable in both the Michigan and Italian econometric models, is the key variable in the Michigan model which explains the divergence of the ex ante and ex post forecasting results.
\end{abstract}

Keywords: Exchange rate forecasts; Structural econometric models; Random walk JEL classification: $\mathrm{F} 47 ; \mathrm{C} 53 ; \mathrm{C} 32 ; \mathrm{C} 22$

\section{Introduction}

Gandolfo, Padoan and Paladino (1990) (GPP) report that out-of-sample forecasts of the lira $/ \$$ exchange rate using a continuous-time model of the Italian economy outperform forecasts of a random-walk model. They offer this result as an antidote to those who would interpret the predictive failure of the single-equation models of the exchange rate examined by Meese and Rogoff $(1983 a, b)$ as a failure of economic theory. While the results obtained from the Italian model are suggestive, it is not clear to what extent they are

Correspondence to: Professor E.P. Howrey, Research Seminar in Quantitative Economics, Department of Economics. The University of Michigan, Ann Arbor, MI 48109-1220, USA.

*I would like to thank Professor Saul IIymans, Director of the Research Seminar in Quantitative Economics, for helpful comments and suggestions on an earlier draft of this paper, Peter Hooper for providing data, Pat Rocco for research assistance, Lawrence R. Klein for suggesting this topic, and members of the NBER/NSF Econometric Model Comparison Seminar for their suggestions and comments. 
specific to the Italian economy or are due to the use of an economy-wide model, a continuous-time model, the particular variables that are taken to be exngenous for purposes of the out-of-sample forecasts, or the particular sample period that was examined.

The purpose of this paper is to present the results of an attempt to replicate the GPP experiment using the Michigan Quarterly Econometric Model (MQEM) of the US economy to forecast a trade-weighted average of the value of the US dollar. A brief overview of MQEM is given in the next section and the exchange-rate equation that is used in MQEM is introduced. For purposes of comparison, a set of single-equation 'structural' models of the exchange rate of the type investigated by Meese and Rogoff (1983a, b) are also introduced. The results of the forecast exercise are discussed in section 3 . Section 4 concludes the paper.

\section{Structural models of the exchange rate}

\subsection{The Michigan Quarterly Econometric Model ${ }^{1}$}

The Michigan Quarterly Econometric Model of the US economy is a forecasting and policy analysis model maintained by the Research Seminar in Quantitative Economics at the University of Michigan and is used to produce forecasts of the US economy on a regular basis. The first version of what is today called MQEM was the now-classic Klein-Goldberger model, an annual model containing 20 equations. The version of the model used for this study contains 206 equations, 99 of which are stochastic.

\subsubsection{Overview of $M Q E M$}

The block structure of MQEM is shown in table 1. Blocks 1 (wages and prices) and 2 (productivity and employment) implicitly comprise the supply side of the model. The basic wage rate, hourly compensation in the private nonfarm sector of the economy, is determined by an expectations-augmented Phillips curve. The corresponding core price index, the nonfarm price deflator, is determined by a variable mark-up on unit labor costs, but also depends on interest rates and crude materials prices.

The aggregate demand sector of the model is represented by the equations in blocks 3, 4, and 5. This part of the model has an IS-LM interpretation which is derived in Green et al. (1991). The IS curve can be derived from the equations in blocks 3 and 4 that explain expenditures and income flows; the LM curve can be obtained from the equations of the monetary sector (block 5). As a result of adaptive expectations and partial adjustment specifications

\footnotetext{
${ }^{1}$ This section draws heavily on Hymans (1990) and Green et al. (1991).
} 
Table 1

Block structure of MQEM.

Block
(1) Wages and prices
(2) Productivity and employment

(3) Expenditures, purchases

(4) Income flows

Principal endogenous variables

Compensation per hour

Private nonfarm GNP deflator

20 GNP component deflators

Three energy price deflators

Index of the exchange value of the dollar

Automobile and truck price indexes

Output per hour

Employment rate, males 20 and over

Aggregate unemployment rate

Unit vehicle sales

US cars and trucks

Imported cars and trucks

Consumption

Autos, new

Autos, net used and parts

Trucks

Furniture and household equipment

Other durables

Five nondurables components

Services

Business fixed investment

Structures

Fquipment

Agriculture

Production

Autos

Trucks

Other

Residential building

Housing starts

Inventory investment

New autos

Trucks

Nonfarm, nonvehicle

Imports

Non-petroleum

Autos, trucks

Exports

Private wages and salaries

Profits

Interest income

Dividends

Other labor income

Nonfarm proprietor income

Farm proprietor income

Govt. unemployment benefits

Taxes

Capital consumption allowances

Interest on government debt

To foreigners

(5) Monetary sector

M1 plus total savings deposits

M2 plus short term treasury securities

Three-month Treasury bill rate

Budget identity

Six term structure equations

Monetary base

Govt. demand deposits

(6) Output composition

Services component of real GNP

Manufacturing index of industrial production Index of available capacity in manufacturing

Gross auto product

Gross truck product 
for many of the equations, the IS and LM curves are much steeper in the short run than in the long run.

\subsubsection{Exchange-rate determination in $M Q E M$}

The exchange rate in MQEM is determined directly by a variable purchasing power parity (PPP) relationship. The structural equation estimated over the period 1973:2-1987:4 is

$$
\begin{aligned}
& \Delta \ln e=0.0021+1.0161 \Delta \ln p_{\mathrm{f}} / p+0.1102 \Delta\left[\ln p_{\mathrm{f}} / p\right]_{-1} \\
& \text { (0.002) (0.044) (0.042) } \\
& +0.0210 \Delta \ln r / r_{\mathrm{f}}+0.0320 \ln [x+k]_{-1} /\left[m+t r+i_{\mathrm{f}}\right], \\
& \text { (0.007) (0.011) }
\end{aligned}
$$

with $R^{2}=0.938$, s.e. $=0.011, \mathrm{DW}=1.82$ and where

$e=$ the trade-weighted value of the US dollar relative to $\mathrm{G}-10$ countries plus Switzerland,

$p_{\mathrm{f}}=$ the implicit deflator for non-oil goods and services imported by the US denominated in foreign currencies

$p=$ the US export price deflator,

$r=$ three-month US Treasury bill rate,

$r_{\mathrm{f}}=$ trade weighted average of three-month foreign interest rates,

$x=$ US exports of goods and services (current dollars),

$k=$ net capital grants received by the US (current dollars),

$m=$ US imports of goods and services (current dollars),

$t r=$ personal and federal government transfers to foreigners (current dollars),

$i_{\mathrm{f}}=$ federal government interest payments to foreigners (current dollars).

If there is no differential between US and foreign interest rates and the (lagged) US current account is in balance, the last two terms in this equation are zero and the exchange rate moves to restore PPP among currencies. The presence of an interest rate differential or a current account imbalance modulates the movement of the exchange rate. In particular, if the US shortterm interest rate exceeds foreign interest rates or the US has a current account surplus, there will be upward pressure on the value of the US dollar. In standard forecasting mode, MQEM takes $p_{\mathrm{f}}, r / r_{\mathrm{f}}, t r$, and $k$ to be exogenous.

\subsection{Single-equation models of the exchange rate}

For purposes of comparison with MQEM, forecasts of single-equation 'structural' models of the exchange rate are also examined. The general form 
of these models is taken from Meese and Rogoff (1983a, b). Let $e_{j t}$ denote the natural logarithm of the exchange rate between the US and country $j$ in period $t$. Then the general form of the exchange-rate equation is

$$
\begin{aligned}
e_{j t}= & \alpha_{j 0}+\alpha_{j 1}\left(m_{t}-m_{j t}\right)+\alpha_{j 2}\left(y_{t}-y_{j t}\right)+\alpha_{j 3}\left(r s_{t}-r s_{j t}\right) \\
& +\alpha_{j 4}\left(r l_{t}-r l_{j t}\right)+\alpha_{j 5}\left(c a_{t}-c a_{j t}\right)+\alpha_{j 6} e_{j t-1}+u_{j t}, \\
u_{j t}= & \rho_{j} u_{j t-1}+v_{j t},
\end{aligned}
$$

where the independent variables are defined as follows:

$m=$ natural logarithm of the money stock,

$y=$ natural logarithm of income,

$r s=$ short-term interest rate,

$r l=$ long-term interest rate,

$c a=$ cumulated current account balance.

A variable with a $t$ subscript designates the US value of the variable at time $t$ and a variable with a $j t$ subscript designates the value of the variable for country $j$ at time $t$.

Three versions of this model were used in the forecasting exercise. The unrestricted equation corresponds to the model developed by Hooper and Morton (1982) and is designated as HM. With the restriction $\alpha_{j 5}=0$ the equation reduces to the model investigated by Dornbusch (1976) and Frankel (1979) and is designated as DF. Finally, with the restrictions $\alpha_{j 4}=\alpha_{j 5}=0$, the equation reduces to the model investigated by Frenkel (1976) and Bilson (1978) and is designated as FB.

In its most general form, eq. (2) includes a lagged dependent variable $e_{j t-1}$ and allows for serial correlation of the disturbance term $u_{j t}$. It turned out to be redundant from the point of view of forecast accuracy to include both lagged adjustment and scrially corrclated disturbances simultancously, so three versions of each model were estimated: (a) $\alpha_{j 6}=\rho_{j}=0$, (b) $\alpha_{j 6}=0$, and (c) $\rho_{j}=0$. Thus variant (a) does not allow for dynamic adjustment of either type, variant (b) allows for autocorrelated disturbances, and variant (c) allows for lagged adjustment of the exchange rate.

Previous research has used variants of this equation to investigate both bilateral exchange rates and an index of bilateral exchange rates. For example, Meese and Rogoff (1983a) report results for both selected bilateral rates and an index of US exchange rates; Hooper and Morton (1982) were concerned exclusively with an average of US exchange rates. In order to obtain forecasts of the trade weighted value of the dollar relative to G-10 
countries plus Switzerland which are required for comparison with MQEM, it is necessary to aggregate (2) over the countries in the index. Two different aggregation procedures were used. The first method involves aggregation of the bilateral exchange rate equation assuming that the coefficients $\alpha_{j k}=\beta_{k}$ and $\rho_{j}=\rho$ for all $j$, i.e., the bilateral coefficients are the same for all countries over which the equation is aggregated. If $w_{j}$ denotes the (fixed) weight attached to $e_{j t}$ in the exchange rate index $e_{t}$, then

$$
e_{\ell}=\sum_{j} w_{j} e_{j t}
$$

The aggregate equation then becomes

$$
\begin{aligned}
e_{t}= & \beta_{0}+\beta_{1}\left(m_{t}-m_{f t}\right)+\beta_{2}\left(y_{t}-y_{f t}\right)+\beta_{3}\left(r s_{t}-r s_{f t}\right)+\beta_{4}\left(r l_{t}-r l_{f t}\right) \\
& +\beta_{5}\left(c a_{t}-c a_{f t}\right)+\beta_{6} e_{t-1}+u_{f t}, \\
u_{f t}= & \rho u_{f t-1}+v_{t}
\end{aligned}
$$

where a variable with the $f t$ subscript denotes a weighted average of the values of the variable for the countries in the index with weights equal to $w_{j}$. The coefficients in this aggregate equation are then estimated and the resulting equation is used to generate forecasts. The second procedure involves estimation of the coefficients in the bilateral equation, using these estimates to generate forecasts of the bilateral exchange rate, and then aggregating the bilateral forecasts using (3).

The first approach, aggregate and then estimate, is the method used by Hooper and Morton (1982) and Meese and Rogoff (1983a). The advantage of this approach is that only one equation is estimated with the index of exchange rates as the dependent variable. The potential disadvantages of this approach are that it assumes at least implicitly that the coefficients in the bilateral exchange rate equation are the same for all countries in the index and the sample is limited to the period for which data are available for all of the countries in the index. The potential advantage of the second approach, estimate and then aggregate, is that it allows the country coefficients to differ and each bilateral equation can be estimated using all the data available for that country.

\section{Empirical results}

The forecast period chosen for study is 1985:1-1990:3. As shown in fig. 1, the value of the dollar declined sharply during the first half of this forecast period and then varied about what appears to be a more normal historical value thereafter. Both one- and four-quarter ahead forecasts of the natural 


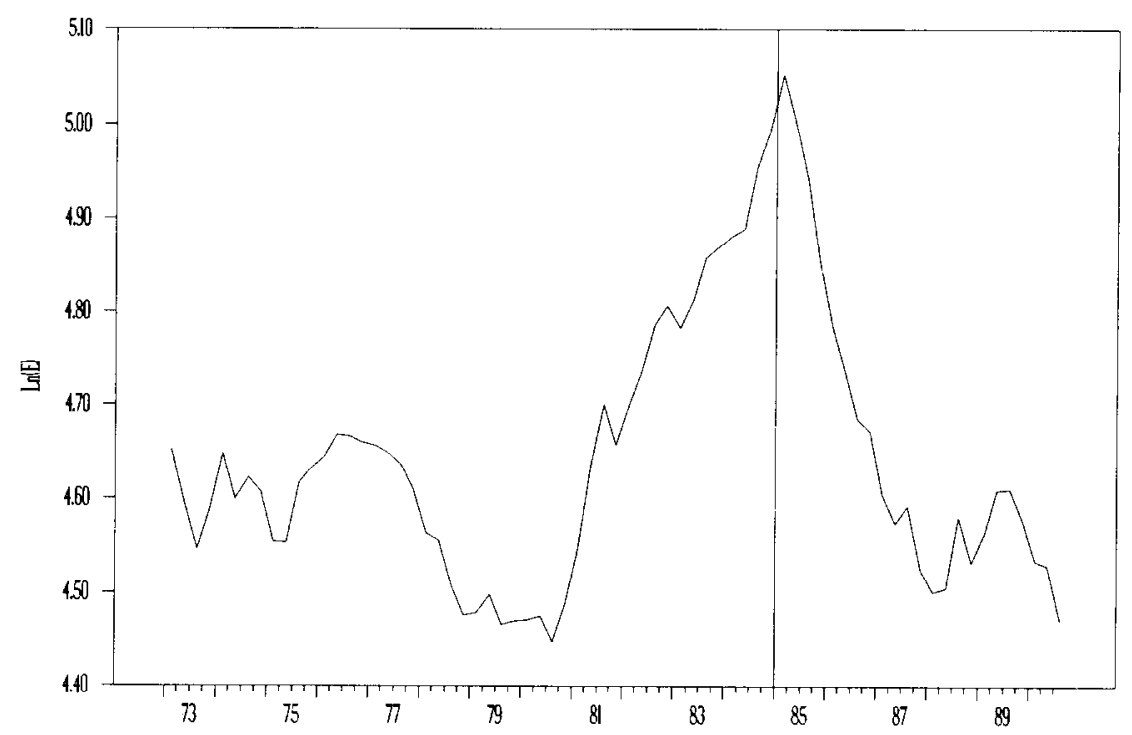

Fig. 1. Logarithm of the trade weighted value of the US dollar, 1973:1-1990:3.

logarithm of the trade weighted value of the dollar were generated. There are thus 23 one-quarter ahead forecasts and 20 four-quarter ahead forecasts.

\subsection{Single-equation forecasts}

The definitions of the variables used to estimate the single-equation models and the sample periods for which they were available are shown in the Data Appendix. When the aggregate eq. (4) was estimated over the period 1982:11990:3, the longest period for which data for all the countries in the exchange rate index were available, the results shown in table 2 were obtained. Based on the Durbin-Watson (DW) statistics, some correction for serial correlation is clearly required for the FB and DF models. And based on the standard error of the estimate (s.e.), the lagged dependent variable version of each of the three models fits the data better than either of the other two variants. For the lagged dependent variable versions of the models, the money stock differential is significant for all three models but the real income differential is not. The evidence on the interest rate differentials in the lagged adjustment models is mixed: the short-term interest rate differential is significant in the FB model, neither the short-term nor the long-term interest rate differential is individually significant in the DF model, and the long-term but not the short-term interest rate differential is significant in the HM lagged adjustment model. Finally, the capital account differential is statistically significant in the HM model. 
Table 2

Parameter estimates of structural models of the aggregate US exchange rate: 1982:1-1990:3.

\begin{tabular}{|c|c|c|c|c|c|c|c|c|c|}
\hline Model & Constant & $m-m_{\mathrm{f}}$ & $y-y_{\mathrm{t}}$ & $r s-r s_{\mathrm{r}}$ & $r l-r l_{\mathrm{r}}$ & $c a-c a_{\mathrm{r}}$ & $e_{-1}$ & $\rho$ & s.e./DW \\
\hline FB (a) & $\begin{array}{c}-5.163 \\
(-4.00)\end{array}$ & $\begin{array}{l}-3.782 \\
(-7.66)\end{array}$ & $\begin{array}{r}8.073 \\
(5.26)\end{array}$ & $\begin{array}{l}-0.022 \\
(-1.32)\end{array}$ & & & & & $\begin{array}{l}0.103 \\
0.472\end{array}$ \\
\hline FB (b) & $\begin{array}{l}-3.568 \\
(-0.59)\end{array}$ & $\begin{array}{l}-1.022 \\
(-1.47)\end{array}$ & $\begin{array}{c}1.071 \\
(0.83)\end{array}$ & $\begin{array}{l}-0.016 \\
(-1.41)\end{array}$ & & & & $\begin{array}{c}0.999 \\
(13.30)\end{array}$ & $\begin{array}{l}0.045 \\
1.552\end{array}$ \\
\hline FB (c) & $\begin{array}{l}-1.055 \\
(-2.03)\end{array}$ & $\begin{array}{l}-0.578 \\
(-2.13)\end{array}$ & $\begin{array}{c}0.325 \\
(0.44)\end{array}$ & $\begin{array}{r}0.017 \\
(2.67)\end{array}$ & & & $\begin{array}{r}0.910 \\
(15.07)\end{array}$ & & $\begin{array}{l}0.035 \\
2.055\end{array}$ \\
\hline $\mathrm{DF}(\mathrm{a})$ & $\begin{array}{l}-2.113 \\
(-1.65)\end{array}$ & $\begin{array}{l}-2.634 \\
(-5.41)\end{array}$ & $\begin{array}{c}0.764 \\
(0.35)\end{array}$ & $\begin{array}{l}-0.091 \\
(-4.22)\end{array}$ & $\begin{array}{c}0.174 \\
(4.12)\end{array}$ & & & & $\begin{array}{l}0.083 \\
0.669\end{array}$ \\
\hline $\mathrm{DF}(\mathrm{b})$ & $\begin{array}{l}-2.193 \\
(-0.44)\end{array}$ & $\begin{array}{l}-0.901 \\
(-1.29)\end{array}$ & $\begin{array}{c}0.740 \\
(2.72)\end{array}$ & $\begin{array}{l}-0.030 \\
(-1.90)\end{array}$ & $\begin{array}{r}0.033 \\
(1.26)\end{array}$ & & & $\begin{array}{r}0.998 \\
(12.00)\end{array}$ & $\begin{array}{l}0.045 \\
1.831\end{array}$ \\
\hline $\mathrm{DF}(\mathrm{c})$ & $\begin{array}{l}-0.782 \\
(-1.44)\end{array}$ & $\begin{array}{l}-0.582 \\
(-2.18)\end{array}$ & $\begin{array}{l}-0.462 \\
(-0.51)\end{array}$ & $\begin{array}{c}0.002 \\
(0.20)\end{array}$ & $\begin{array}{c}0.031 \\
(1.44)\end{array}$ & & $\begin{array}{r}0.851 \\
(11.81)\end{array}$ & & $\begin{array}{l}0.033 \\
2.081\end{array}$ \\
\hline $\mathrm{HM}$ (a) & $\begin{array}{c}0.226 \\
(0.35)\end{array}$ & $\begin{array}{l}-1.744 \\
(-7.13)\end{array}$ & $\begin{array}{c}2.964 \\
(2.85)\end{array}$ & $\begin{array}{l}-0.074 \\
(-7.23)\end{array}$ & $\begin{array}{c}0.095 \\
(4.43)\end{array}$ & $\begin{array}{c}0.084 \\
(10.16)\end{array}$ & & & $\begin{array}{l}0.039 \\
1.829\end{array}$ \\
\hline HM (b) & $\begin{array}{c}0.274 \\
(0.40)\end{array}$ & $\begin{array}{l}-1.727 \\
(-6.67)\end{array}$ & $\begin{array}{c}2.946 \\
(2.72)\end{array}$ & $\begin{array}{r}-0.073 \\
(-6.81)\end{array}$ & $\begin{array}{r}0.093 \\
(4.21)\end{array}$ & $\begin{array}{c}0.084 \\
(9.63)\end{array}$ & & $\begin{array}{c}0.051 \\
(0.23)\end{array}$ & $\begin{array}{l}0.040 \\
1.911\end{array}$ \\
\hline $\mathrm{HM}(\mathrm{c})$ & $\begin{array}{c}-0.330 \\
(-0.59)\end{array}$ & $\begin{array}{r}-0.933 \\
(-3.03)\end{array}$ & $\begin{array}{r}0.801 \\
(0.75)\end{array}$ & $\begin{array}{l}-0.023 \\
(-1.35)\end{array}$ & $\begin{array}{r}0.049 \\
(2.19)\end{array}$ & $\begin{array}{c}0.032 \\
(2.01)\end{array}$ & $\begin{array}{c}0.563 \\
(3.55)\end{array}$ & & $\begin{array}{l}0.033 \\
2.081\end{array}$ \\
\hline
\end{tabular}

a $t$-Statistics are shown in parentheses.

Table 3

Root mean squared errors of in-sample forecasts of the US exchange rate (ln E): 1985:1-1990:3.

\begin{tabular}{llllll}
\hline & \multicolumn{2}{l}{$\begin{array}{l}\text { Aggregate equation: } \\
\text { forecast horizon }\end{array}$} & & \multicolumn{2}{l}{$\begin{array}{l}\text { Bilateral equations: } \\
\text { forecast horizon }\end{array}$} \\
\cline { 2 - 3 } Model & 1 Qtr. & 4 Qtr. & & 1 Qtr. & 4 Qtr. \\
\hline FB (a) & 0.1113 & 0.1097 & & 0.1372 & 0.1032 \\
FB (b) & 0.0436 & 0.0968 & & 0.0443 & 0.1074 \\
FB (c) & 0.0364 & 0.0477 & & 0.0401 & 0.0805 \\
DF (a) & 0.0828 & 0.0885 & & 0.1115 & 0.0901 \\
DF (b) & 0.0407 & 0.0881 & & 0.0447 & 0.1099 \\
DF (c) & 0.0341 & 0.0443 & & 0.0398 & 0.0786 \\
HM (a) & 0.0355 & 0.0378 & & 0.0796 & 0.06311 \\
HM (b) & 0.0355 & 0.0377 & & 0.0390 & 0.0800 \\
HM (c) & 0.0312 & 0.0353 & & 0.0396 & 0.0806 \\
RW & 0.0495 & 0.1431 & & 0.0495 & 0.1431 \\
\hline
\end{tabular}

When the estimated equations shown in table 2 were used to generate oneand four-quarter ahead forecasts for the period 1985:1-1990:3, the results shown in table 3 were obtained. These forecasts are not true ex ante forecasts for two reasons: the entire sample period including the forecast period is 
used to estimate the coefficients in the equations and the independent variables are set equal to their actual values. For models with a lagged dependent variable or autocorrelated disturbance term, one-quarter ahead forecasts used the actual value of the lagged dependent variable or lagged residual; four-quarter ahead forecasts were generated sequentially with predicted values for the lagged dependent variable or lagged residual. For purposes of comparison, the forecasts of a random-walk model, $\mathrm{RW}$, are also included.

The results for the in-sample forecasts shown in table 3 indicate that the best forecasts are produced by the lagged dependent variable versions of all three model, a result that might have been anticipated on the basis of the standard errors of the regression equations reported in table 2 . The aggregate equations produce slightly more accurate forecasts than the aggregated bilateral equations for the one-quarter ahead forecasts and much better fourquarter ahead forecasts. Finally, notice that the lagged dependent variable versions of these models produce forecasts that have smaller root mean squared forecast errors than the random walk model. The differences in rmse values are much larger for the four-quarter ahead forecasts than for the onequarter ahead forecasts. The finding that the random walk is dominated by the aggregate structural equations is not that surprising since the lagged dependent variable versions of the models encompass the random-walk model as a special case and the least squares estimates of the coefficients ensure the best possible fit over a period that includes the forecast period.

A more rigorous test of the single-equation models is provided by rollingregression forecasts in which the model is estimated using data prior to the forecast period. The results of a rolling-regression experiment are shown in table 4. The key point that emerges from these calculations is that with only a few exceptions, the random-walk forecasts are more accurate than the single-equation forecasts. It is interesting to note that the bilateral approach produces more accurate one-quarter ahead forecasts than the corresponding aggregate approach, but the improvement over the random-walk forecasts is negligible. For the four-quarter ahead forecasts, only the aggregate DF modcl with autocorrelated disturbances produces better forceasts than the random walk, and again the difference in accuracy is relatively small.

The conclusion from these forecasting experiments is that it is possible to construct single equation 'structural' models of the exchange rate index that generate more accurate in-sample forecasts than the random walk, but this superiority does not extend to out-of-sample forecasts.

\subsection{MQEM forecasts}

The root mean squared errors (rmse) of the alternative MQEM forecasts are shown in table 5. For one-quarter ahead forecasts, the simple random 
Table 4

Root mean squared errors of rolling-regression forecasts of the US exchange rate (ln E): 1985:1-1990:3. ${ }^{\mathrm{a}}$

\begin{tabular}{llllll}
\hline & \multicolumn{2}{l}{$\begin{array}{l}\text { Aggregate equation: } \\
\text { forecast horizon }\end{array}$} & & \multicolumn{2}{l}{$\begin{array}{l}\text { Bilateral equations: } \\
\text { forecast horizon }\end{array}$} \\
\cline { 2 - 3 } Model & 1 Qtr. & 4 Qtr. & & 1 Qtr. & 4 Qtr. \\
\hline FB (a) & 0.1273 & 0.1745 & & 0.1704 & 0.2301 \\
FB (b) & 0.0649 & 0.1688 & & 0.0512 & 0.1505 \\
FB (c) & 0.0488 & 0.2029 & & 0.0464 & 0.1417 \\
DF (a) & 0.1043 & 0.1589 & & 0.1499 & 0.2102 \\
DF (b) & 0.0670 & 0.1120 & & 0.0532 & 0.1638 \\
DF (c) & 0.0506 & 0.2117 & & 0.0471 & 0.1489 \\
HM (a) & 0.0688 & 0.1806 & & 0.1187 & 0.2587 \\
HM (b) & 0.0764 & 0.1758 & & 0.0504 & 0.1744 \\
HM (c) & 0.0589 & 0.2462 & & 0.0513 & 0.2098 \\
RW & 0.0495 & 0.1431 & & 0.0495 & 0.1431 \\
\hline
\end{tabular}

${ }^{a}$ The rolling-regression forecasts are based on estimates of the model coefficients that use only data prior to the forecast period.

Table 5

Root mean squared errors of MQEM forecasts of the US exchange rate $(\ln E):$ 1985:1-1990:3.

\begin{tabular}{lcc}
\hline & \multicolumn{2}{l}{ Forecast horizon } \\
\cline { 2 - 3 } Model & 1 Qtr. & 4 Qtr. \\
\hline Random walk & 0.0495 & 0.1431 \\
Random walk with drift & 0.0508 & 0.1250 \\
MQEM single equation & 0.0097 & 0.0285 \\
MQEM complete model & 0.0125 & 0.0441 \\
MQEM augmented model $\Lambda$ & 0.0120 & 0.0420 \\
MQEM augmented model B & 0.0470 & 0.1519 \\
MQEM augmented model C & 0.0575 & 0.1950 \\
\hline a The single-equation forecasts (random walk with drift and \\
MQEM single equation) are based on rolling-regression estimates of \\
the model coefficients using only data prior to the forecast period. \\
For the full-model forecasts, the exchange rate equation is estimated \\
over the period 1973:2-1987:4.
\end{tabular}

walk model has a rmse of 0.0495 or $4.95 \%$, since it is the natural logarithm of the exchange rate that is being predicted. The rmse of the four-quarter ahead forecasts from the simple random walk model is $14.31 \%$. As seen in the second row of entries in the table, it makes little difference in terms of forecast accuracy whether or not a constant term is included in the random walk model.

Using the MQEM exchange-rate equation as a single-equation model with all of the explanatory variables in the equation taken as exogenous results in 
a dramatic improvement in the accuracy of the exchange-rate forecasts. The rmse of one-quarter ahead rolling-regression forecasts falls to $0.97 \% \mathrm{com}$ pared to $4.95 \%$ for the random-walk model, and for the four-quarter ahead forecasts the rmse is $2.85 \%$ compared to $14.35 \%$ for the random-walk model. Even when the exchange-rate equation is embedded in the full model so that the cxchangc ratc, the export deflator, the value of exports and the value of imports are forecast simultaneously with all of the other endogenous variables of the model, the exchange-rate forecasts are still much more accurate than the random-walk forecasts. The rmse of one-quarter ahead forecasts is now $1.25 \%$ and the rmse of four-quarter ahead forecasts is $4.41 \%$; both well below the corresponding rmse values for the random-walk forecasts. $^{2}$

The use of an economy-wide forecasting model for the US economy produces exchange-rate forecasts that are decidedly superior to those produced by a random-walk model. These full-model forecasting results for the US economy are consistent with the results obtained by Gandolfo, Padoan, and Paladino for the Italian economy using a continuous-time simultaneous equations model. This indicates that the GPP results are not specific to the Italian economy nor necessarily due to the use of a continuous-time model.

The full-model forecasts take both $p_{\mathrm{f}}$ and $r / r_{\mathrm{f}}$ as exogenous and hence given. This gives the structural model the 'benefit of the doubt' as a descriptive model, but leaves unanswered the question of how well the model would perform relative to the random-walk model in a true ex ante forecasting exercise. In an attempt to answer that question, it is necessary to augment the model to explain these two potentially critical variables, $p_{\mathrm{f}}$ and $r / r_{\mathrm{f}}$. This is done in two steps: first an equation is added to explain $r / r_{\mathrm{f}}$, and then an equation is added to explain $p_{\mathrm{r}}$. The interest rate differential equation is based on the notion that foreign interest rates respond with a distributed lag to changes in the US rate. The empirical equation estimated over the period 1973:3-1990:3 is

$$
\begin{aligned}
\ln r / r_{\mathrm{f}}= & -0.1287+0.7622 \ln r-0.7166 \ln r_{-1}+0.5735 \ln \left[r / r_{\mathrm{f}}\right]_{-1} \\
& (0.176)(0.067) \quad(0.082) \\
& +0.7133 u_{-1}, \\
& (0.139)
\end{aligned}
$$

with $R^{2}=0.911$, s.e. $=0.062$, and $\mathrm{DW}=1.76$. (The term $u_{-1}$ indicates that the equation was estimated with a correction for first-order serial correlation.)

\footnotetext{
${ }^{2}$ The single-equation forecasts (random walk with drift and MQEM single equation) are rolling-regression forecasts in which the coefficients were estimated using data prior to the forecast period; for the full-model forecasts, the exchange rate equation is estimated over the period 1973:2-1987:4.
} 
When this equation is added to the model, $r_{\mathrm{f}}$ becomes an endogenous variable since the domestic interest rate, $r$, is an endogenous variable in MQEM. The forecast results, shown as MQEM augmented model $\mathrm{A}$ in table 5 , indicate that the root mean square forecast errors of both the one- and four-quarter ahead forecasts fall slightly. We therefore conclude that prior knowlcdge of the actual interest rate differential is not critical in forecasting the exchange rate.

An equation is also needed for $p_{\mathrm{f}}$ to complete this experiment. Using the standard Box-Jenkins modelling procedure, a univariate $\operatorname{ARIMA}(1,1,0)$ equation was found using data for the period 1973:2-1990:3:

$$
\begin{gathered}
\Delta \ln p_{\mathrm{f}}=0.0112+0.4042 \Delta \ln \left[p_{\mathrm{f}}\right]_{-1}, \\
(0.007) \quad(0.113)
\end{gathered}
$$

with $R^{2}=0.158$, s.e. $=0.037, \mathrm{DW}=2.03$. When this equation is appended to the model, the results shown as MQEM augmented model $B$ in table 4 were obtained. These results indicate that better forecasts of $p_{\mathrm{f}}$ than those produced by a 'naive' time series model are necessary in order to obtain the result that MQEM delivers better forecasts of the exchange rate than the random-walk model.

Notice, however, that the simple time series model for $\ln p_{\mathrm{f}}$ does not produce a very good fit; the standard error of the estimate is 0.037 or $3.7 \%$. A much better fit can be obtained with a bivariate model in which the change in the logarithm of $p_{\mathrm{f}}$ responds with a distributed lag to the change in the logarithm of the domestic US price level expressed in terms of foreign currency:

$$
\Delta \ln p_{\mathrm{f}}=0.8233 \Delta \ln c p i^{*} e-0.5708 \Delta \ln \left[c p i^{*} e\right]_{-1}+0.6224 \Delta \ln \left[p_{\mathrm{f}}\right]_{-1},
$$

with $R^{2}=0.918$, s.e. $=0.012, \mathrm{DW}=2.07$. However, when this equation is added to the model, the results shown as MQEM augmented model $\mathrm{C}$ in table 5 were obtained. Even though this simple 'pricing to market' equation for $p_{\mathrm{f}}$ fits the data rather well, when combined with the rest of the model it produces forecasts of the exchange rate which are worse than those of the random-walk model. A number of variations on this model were tried including dropping the contemporaneous value of $\Delta \ln c p i^{*} e$ from the equation and entering $\Delta \ln c p i_{-1}$ and $\Delta \ln e_{-1}$ separately. All such attempts were unsuccessful in terms of obtaining a model with improved ex ante forecast accuracy.

While the results in table 5 indicate that it is possible to find a structural equation which will produce better outside-sample forecasts than the random-walk model, they do not address the question of the statistical significance of the differences in forecast accuracy. The results of three tests 
Table 6

Tests against the random-walk model. ${ }^{a}$

\begin{tabular}{|c|c|c|c|c|c|c|}
\hline \multirow[b]{3}{*}{ Model } & \multicolumn{6}{|c|}{ Forecast horizon } \\
\hline & \multicolumn{3}{|c|}{1 Quarter } & \multicolumn{3}{|c|}{4 Quarters } \\
\hline & W-K & $\mathrm{W}-\mathrm{K}^{*}$ & D-M & W-K & W-K* & D-M \\
\hline MQEM single equation & 11.33 & 13.42 & 5.31 & 12.75 & 14.17 & 2.21 \\
\hline MQEM complete model & 8.71 & 11.67 & 5.08 & 6.96 & 4.46 & 2.01 \\
\hline MQEM augmented model $A$ & 9.09 & 12.02 & 5.12 & 7.50 & 4.84 & 2.04 \\
\hline MQEM augmented model $B$ & 0.50 & 0.46 & 0.46 & -0.81 & -0.62 & -0.59 \\
\hline MQEM augmented model $\mathrm{C}$ & -0.72 & -0.84 & -0.75 & -1.56 & -0.76 & -0.75 \\
\hline
\end{tabular}

a The MQEM single-equation forecasts are based on rolling-regression estimates of the model coefficients using only data prior to the forecast period. For the full-model forecasts, the exchange rate equation is estimated over the period 1973:2-1987:4.

of significance are shown in table 6 . The test designated by $\mathrm{W}-\mathrm{K}$ is the Williams-Kloot described in Williams (1959), the test designated by W-K* is the Williams-Kloot test corrected for heteroskedasticity and serial correlation, and D-M is the test statistic proposed by Diebold and Mariano (1991). Let $f_{1}$ and $f_{2}$ denote alternative forecasts of the variable $y$ and let $e_{1}$ and $e_{2}$ denote the corresponding forecast errors. The $\mathrm{W}-\mathrm{K}$ test statistic is the $t$-ratio for a test of the hypothesis that the coefficient of $f_{1}-f_{2}$ is zero in the regression of $y-\left(f_{1}+f_{2}\right) / 2$ on $f_{1}-f_{2}$. A significant $t$-ratio leads to a rejection of the hypothesis that the forecast error variance is the same for the two forecasts. The W-K* statistic for the one-quarter ahead forecasts corrects the $t$-statistic for heteroskedasticity and the $\mathrm{W}-\mathrm{K}^{*}$ statistic for the fourquarter ahead forecasts corrects for heteroskedasticity and for third-order serial correlation using the estimator proposed by Newey and West (1987). The D-M test involves a test of the hypothesis that the mean difference $d=e_{1}{ }^{2}-e_{2}{ }^{2}$ is zero with an appropriate correction for serial correlation in the $d$ series.

The results of these tests uniformly agree that for both one- and fourquarter ahead forecasts, the MQEM single equation forecasts, the MQEM complete model forecasts, and the MQEM augmented model $\Lambda$ forecasts have significantly smaller mean squared errors than the random-walk forecasts. On the other hand, the MQEM augmented model B and model C forecasts have root mean squared errors that do not differ significantly from the random-walk forecasts.

\section{Conclusion}

The results of this paper indicate that standard single-equation 'structural' models of the exchange rate do not produce appreciably better out-of-sample forecasts of an index of US exchange rates than a random walk. However, 
the structural equation for the exchange value of the US dollar in the Michigan Quarterly Econometric Model of the US economy does produce significantly better out-of-sample forecasts than a random-walk model. Even when the exchange-rate equation is embedded in the full model so that the exchange rate, the export deflator, the value of exports and the value of imports are forecast simultancously with all of the other endogenous variables of the model, the exchange-rate forecasts are still much more accurate than the random-walk forecasts. However, the results are extremely sensitive to the particular variables that are specified as exogenous and hence taken as given for the out-of-sample forecasts. In particular, one of the key variables is the price of US imports denominated in foreign currencies. With this variable taken as exogenous, as it is in the experiments reported by Gandolfo, Padoan, and Paladino for the Italian economy, the MQEM outof-sample forecasts are strikingly more accurate than those produced by the random-walk model. But if the import price must be predicted in advance, as would be necessary in a true ex ante forecast, the decided edge in forecast accuracy of MQEM disappears.

The results of this paper illustrate a general and well-known problem in the use of conditional (ex post) forecasts to compare and evaluate different models. And that is that one model may produce much better forecasts than another, not because it is a better forecasting model, but because the information set on which its forecasts are based is much more informative. This potential difficulty is especially acute in the comparison and evaluation of economy-wide models which often contain a large number of exogenous variables. It is important to standardize the information set on which forecasts from alternative models are based in order to draw inferences about model reliability from a comparison of ex post forecasts.

\section{Data appendix}

The data used to estimate the aggregate and bilateral exchange rate equations were obtained from various sources including the Division of International Finance of the Board of Governors of the Federal Reserve System, the Federal Reserve Bank of St. Louis, and the Research Seminar in Quantitative Economics at the University of Michigan. Real GNP was used to measure income, narrowly defined money (M1) was used to measure the money supply, a three-month Treasury bill rate or interbank interest rate was used for the short-term interest rate, and bellwether bond yields were used to measure the long-term interest rate.

The aggregate exchange rate is a trade-weighted average of the ten bilateral exchange rates with the weights shown in the following table. The sample periods for which the data for each of the G-10 countries plus Switzerland were available are also shown in the table. 


\begin{tabular}{lcl}
\hline Country & Weight & Sample period \\
\hline Belgium & 6.4 & $75: 1-90: 3$ \\
Canada & 9.1 & $71: 1-90: 3$ \\
France & 13.1 & $73: 1-90: 3$ \\
Germany & 20.8 & $73: 1-90: 3$ \\
Italy & 9.0 & $75: 1-90: 3$ \\
Japan & 13.6 & $77: 2-90: 3$ \\
Netherlands & 8.3 & $75: 1-90: 3$ \\
Sweden & 4.2 & $82: 1-90: 3$ \\
Switzerland & 3.6 & $74: 1-91: 3$ \\
United Kingdom & 11.9 & $73: 3-90: 3$ \\
\hline
\end{tabular}

\section{References}

Bilson, J.F.O., 1978, The current experience with floating exchange rates: An appraisal of the monetary approach, American Economic Review: Papers and Proceedings 68, 392-397.

Diebold, F.X. and R.S. Mariano, 1991, Comparing predictive accuracy I: Asymptotic tests, Manuscript, Department of Economics, University of Pennsylvania, Philadelphia, PA.

Dornbusch, R., 1976, Expectations and exchange rate dynamics, Journal of Political Economy 84, 1161-1176.

Frankel, J.A., 1979, On the mark: A theory of floating exchange rates based on real interest differentials, American Economic Review 69, 610-622.

Frenkel, J.A., 1976, A monetary approach to the exchange rate: Doctrinal aspects and empirical evidence, Scandinavian Journal of Economics 78, 200-224.

Gandolfo, G., P.C. Padoan and G. Paladino, 1990, Exchange rate determination: Single-equation or economy-wide models?: A test against the random walk, Journal of Banking and Finance $14,965-992$.

Green, R.J., B.G. Hickman, E.P. Howrey, S.H. Hymans and M.R. Donihue, 1991, The IS-LM cores of three econometric models, in: L.R. Klein, ed., Comparative performance of U.S. econometric models (Oxford University Press, New York, NY), chap. 4.

Hooper, P. and J.E. Morton, 1982, Fluctuations in the dollar: A model of nominal and real exchange rate determination, Journal of International Money and Finance 1, 39-56.

Hymans, S.H., 1990, The Michigan Quarterly Econometric Model of the U.S. economy: Structure and dynamic properties, Prepared for U.S./U.S.S.R. Economic-Mathematical Macromodeling Conference, Moscow/Sochi, U.S.S.R., June 10-17.

Meese, R.A. and K. Rogoff, 1983a, Empirical exchange rate models of the seventies: Do they fit out of sample?, Journal of International Economics 14, 3-24.

Meese, R. and K. Rogoff, 1983b, The out-of-sample failure of empirical exchange rate models: Sampling error or misspecification?, in: J.A. Frenkel, ed., Exchange rates and international macroeconomics (University of Chicago Press, Chicago, IL), chap. 3.

Newey, W.K. and K.D. Wcst, 1987, A simplc positivc-definitc hetcroskedasticity and autocorrelation consistent covariance matrix, Econometrica 55, 703-708.

Williams, E.J., 1959, Regression analysis (Wiley, New York, NY). 